\title{
Sulfur-Tolerant, Exsolved Fe-Ni Alloy Nanoparticles for CO Oxidation
}

\author{
Evangelos I. Papaioannou ${ }^{1}$ (D) Dragos Neagu' ${ }^{1} \cdot$ Wan K. W. Ramli ${ }^{1,2} \cdot$ John T. S. Irvine ${ }^{3} \cdot$ Ian S. Metcalfe ${ }^{1}$
}

Published online: 5 October 2018

(c) The Author(s) 2018

\begin{abstract}
Metallic nanoparticles exsolved at the surface of perovskite oxides have been recently shown to unlock superior catalytic activity and durability towards various chemical reactions of practical importance. For example, for the $\mathrm{CO}$ oxidation reaction, exsolved Ni nanoparticles in oxidised form exhibit site activities approaching those of noble metals. This is of particular interest for the prospect of replacing noble metals with earth-abundant metal/metal oxide catalysts in the automotive exhaust control industry. Here we show that for the $\mathrm{CO}$ oxidation reaction, the functionality of exsolved Ni nanoparticles can be further improved when $\mathrm{Fe}$ is co-exsolved with $\mathrm{Ni}$, as $\mathrm{Fe}-\mathrm{Ni}$ alloy nanoparticles, eventually forming mixed oxide nanoparticles. As compared to the Ni nanoparticles, the alloy nanoparticles exhibit higher site activities, greatly improved durability over $170 \mathrm{~h}$ of continuous testing and increased tolerance towards sulphur-based atmospheres. Similarly to the single metal nanoparticles, the alloys demonstrate outstanding microstructural stability and high tolerance towards coking. These results open additional directions for tailoring the activity and durability of exsolved materials for the CO oxidation reaction and beyond.
\end{abstract}

Keywords Exsolution $\cdot$ Perovkites $\cdot$ Metal nanoparticles $\cdot$ Sulphur tolerance $\cdot$ CO oxidation

\section{Introduction}

The carbon monoxide (CO) oxidation reaction is of key importance in the area of automotive exhaust treatment, i.e. in three-way catalytic converters [1]. Recently, it has been shown that the exsolution of base metal nanoparticles from perovskite oxides may unlock superior catalytic activity towards the $\mathrm{CO}$ oxidation reaction [2]. For example, exsolved nickel (Ni) nanoparticles can exhibit nominal turnover frequencies (nTOF, number of $\mathrm{CO}$ molecules converted to $\mathrm{CO}_{2}$ per second, per exposed metal atom site) of the order of hundreds s ${ }^{-1}$. This is orders of magnitude higher

Evangelos I. Papaioannou and Dragos Neagu have contributed equally to this work.

Evangelos I. Papaioannou

evangelos.papaioannou@ncl.ac.uk

$\checkmark$ Dragos Neagu

Dragos.Neagu@newcastle.ac.uk

1 School of Chemical Engineering and Advanced Materials, Newcastle University, Newcastle-upon-Tyne NE1 7RU, UK

2 School of Bioprocess Engineering, University Malaysia Perlis, 02600 Arau, Perlis, Malaysia

3 School of Chemistry, University of St Andrews, St Andrews KY16 9ST, UK than the values typically reported for base metal/metal oxide nanoparticles in literature and approaching values observed for noble metals [3]. This unusually high catalytic activity, along with high resistance to carbon deposition, has been assigned to the confined nature of exsolved nanoparticles which are socketed within the perovskite oxide support [4]. The socketed structure is believed to form as a result of the exsolution process itself $[5,6]$. That is, initially the base metal ions, e.g. $\mathrm{Ni}^{2+}$, are substituted in the perovskite oxide lattice in oxidising conditions, and upon exposure to reducing conditions, they emerge at the surface forming metallic nanoparticles [7].

So far, the approach used to further enhance the catalytic activity of exsolved $\mathrm{Ni}$ particles for $\mathrm{CO}$ oxidation, has been through particle restructuring via alloying with cobalt (Co) to trigger the Kirkendall effect [8], in a so-called "chemistry at a point" concept [2]. On the other hand, the effect of alloying on its own has yet to be explored, even though many bimetallic catalyst systems generally show superior performance as compared to their single metal counterparts, probably due to changes in electronic and structural parameters [9-15]. While cobalt oxides have been considered as one of the most promising candidates for use in bimetallic systems for $\mathrm{CO}$ oxidation due to its high activity [16], the stability of Co-based catalysts may be compromised among 
other factors by the presence of poisons, such as sulphur, and further potential restructuring due to the Kirkendall effect. Iron $(\mathrm{Fe})$ has received significant attention as an alternative alloying metal for Ni-based systems because of its lower cost and toxicity, as compared to $\mathrm{Co}$, and high abundance. Furthermore, Fe performs well in catalysing oxidation reactions in rich and lean oxidation environments due to the high capacity of reactive lattice oxygen species $[17,18]$.

Here we investigate the catalytic activity of exsolved $\mathrm{Fe}-\mathrm{Ni}$ bimetallic alloy nanoparticles for the $\mathrm{CO}$ oxidation reaction and demonstrate that they exhibit enhanced site activity and durability as compared to the $\mathrm{Ni}$ variant and other base-metal systems prepared by conventional routes. Additionally, we investigate their catalytic behaviour under $\mathrm{CO}$-rich conditions of the $\mathrm{CO}$ oxidation reaction and observe high tolerance against carbon deposition (coking) whilst maintaining high catalytic activity and structural integrity. Furthermore, Fe-Ni nanoparticles also display improved $\mathrm{SO}_{2}$ tolerance. To illustrate the above, we employ two perovskite oxide systems, $\mathrm{La}_{0.8} \mathrm{Ce}_{0.1} \mathrm{Ni}_{0.4} \mathrm{Ti}_{0.6} \mathrm{O}_{3}$ and $\mathrm{La}_{0.5} \mathrm{Sr}_{0.4} \mathrm{Fe}_{0.1} \mathrm{Ni}_{0.1} \mathrm{Ti}_{0.6} \mathrm{O}_{3}$ in order to enable exsolution of $\mathrm{Ni}$ and $\mathrm{Fe}-\mathrm{Ni}$ alloy nanoparticles, respectively. It should be noted that, whilst the initial exsolved particles were metallic (Ni metal or Fe-Ni alloy), these evolved into oxidised particles to yield the most active phases throughout the series of experiments discussed herein. These systems were labelled $\mathrm{Ni} / \mathrm{p}$ and $\mathrm{Fe}-\mathrm{Ni} / \mathrm{p}$, to denote $\mathrm{Ni}$ and $\mathrm{Fe}-\mathrm{Ni}$-based oxide particles formed after the oxidation of respective exsolved particles from a perovskite host (p). We prepared dense pellets of these two materials and exsolved particles at the top surface, to serve as model catalyst systems (Fig. 1). This catalyst microstructure allowed us to quantify various nanoparticle characteristics (e.g. size, population etc.) by using computed micrograph analysis, and link particle characteristics to catalytic and kinetic behaviour.

\section{Experimental}

\subsection{Catalyst Preparation}

The perovskite oxide pellets were prepared by a modified solid state synthesis. High purity precursors including lanthanum oxide $\left(\mathrm{La}_{2} \mathrm{O}_{3}\right)$ from Pi-Kem $(>99.99 \%)$, cerium oxide $\left(\mathrm{CeO}_{2}\right)$ from Alfa Aesar (>99.99\%), titanium oxide $\left(\mathrm{TiO}_{2}\right)$ from Alfa Aesar (>99.6\%), nickel(II) nitrate hexahydrate $\left(\mathrm{Ni}\left(\mathrm{NO}_{3}\right)_{2} \cdot 6 \mathrm{H}_{2} \mathrm{O}\right)$ from Acros $(>99 \%)$ and iron(III) nitrate nonahydrate $\left(\mathrm{Fe}\left(\mathrm{NO}_{3}\right)_{3} \cdot 9 \mathrm{H}_{2} \mathrm{O}\right)$ from Alfa Aesar $(>99.6 \%)$ were used in the appropriate stoichiometric ratios. Oxides were dried at different temperatures $\left(\mathrm{TiO}_{2}-300{ }^{\circ} \mathrm{C}\right.$, $\mathrm{La}_{2} \mathrm{O}_{3}-800{ }^{\circ} \mathrm{C}$ ) and weighed while warm. The reaction mixture was quantitatively transferred to a beaker and mixed with acetone and $~ 0.05 \mathrm{wt} \%$ Hypermer KD1 dispersant. An ultrasonic Hielscher UP200S probe was used to break down agglomerates and homogenize the mixture into a fine, stable dispersion. The acetone was then evaporated at room temperature under continuous stirring and the resulting powder was calcined at $1000^{\circ} \mathrm{C}$ for $12 \mathrm{~h}$.

The calcined powder was then pressed into $20 \mathrm{~mm}$ diameter pellets $(\sim 1.5 \mathrm{~g}$ of powder per pellet) and fired at $1390{ }^{\circ} \mathrm{C}$ for $16 \mathrm{~h}$ to form the perovskite phase in dense pellet form (relative density $>95 \%$ ). The sintered pellets had a diameter of $15-16 \mathrm{~mm}$ and were polished on the top side to enable particle exsolution at this side only [2]. Polishing was carried out on a Metaserv 2000 polisher, using MetPrep P1200 polishing paper, followed by cloth polishing with MetPrep 6, 3 and $1 \mu \mathrm{m}$ diamond paste, respectively. The samples were cleaned in between each steps with acetone in an ultrasonic bath. In order to trigger exsolution, the pellets were then reduced under a continuous flow of $5 \% \mathrm{H}_{2} / \mathrm{Ar}$ $\left(20 \mathrm{~mL} \mathrm{~min}^{-1}\right)$, at $900{ }^{\circ} \mathrm{C}$, for $30 \mathrm{~h}$, with heating and cooling rates of $5^{\circ} \mathrm{C} \mathrm{min}^{-1}$.

\subsection{Catalyst Characterisation}

Phase purity and crystal structure of the perovskite oxides were confirmed by X-ray diffraction (XRD) by using a PANalytical Empyrean Diffractometer operated in reflection mode. Catalyst morphology was investigated by scanning electron microscopy (SEM), JEOL JSM-6700F before and after catalytic testing. The principle used to map particles and calculated their size distribution and population is described in our previous work [2]. SEM micrographs were converted to binary images based on pixel contrast. From this, the number of particles as well as the diameter of individual particles can be calculated by using dedicated computer software and code as available e.g. through ImageJ
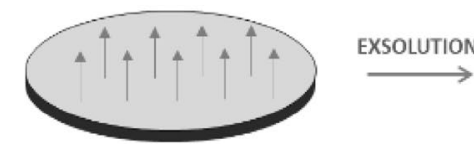
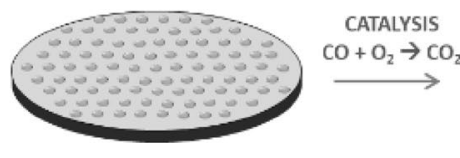

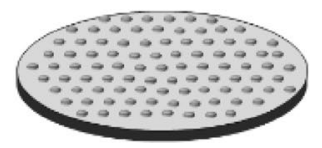

Fig. 1 Model catalyst samples. Schematics of exsolution of metallic nanoparticles at the top surface of dense pellet perovskite oxide samples. Before and after the catalytic tests the pellet is loaded in the electron microscope to examine the particle characteristics and link them to the observed catalytic and kinetic behavior 
Table 1 Particle characteristics for the $\mathrm{Ni} / \mathrm{p}$ and $\mathrm{Fe}-\mathrm{Ni} / \mathrm{p}$ catalysts, including: average particle size, particle population and pellet area $A$ and exposed metal particle area per catalyst area $A_{e}$

\begin{tabular}{|c|c|c|c|c|}
\hline & \multicolumn{2}{|c|}{ As-prepared (metallic) } & \multicolumn{2}{|c|}{$\begin{array}{l}\text { After temperature dependence } \\
\text { experiments (oxidised form) }\end{array}$} \\
\hline & $\mathrm{Ni} / \mathrm{p}$ & $\mathrm{Fe}-\mathrm{Ni} / \mathrm{p}$ & $\mathrm{Ni} / \mathrm{p}$ & $\mathrm{Fe}-\mathrm{Ni} / \mathrm{p}$ \\
\hline Catalyst area, $\mathrm{A}\left(\mathrm{m}^{2}\right)$ & $2 \times 10^{-4}$ & $2 \times 10^{-4}$ & $2 \times 10^{-4}$ & $2 \times 10^{-4}$ \\
\hline Particle size (nm) & $31 \pm 3$ & $35 \pm 3$ & $36 \pm 3$ & $50 \pm 3$ \\
\hline Particle population $\left(\mu \mathrm{m}^{-2}\right)$ & $123 \pm 10$ & $65 \pm 5$ & $128 \pm 10$ & $63 \pm 5$ \\
\hline $\begin{array}{l}\text { Metal area per catalyst area, } A_{e} \\
\left(\mathrm{~m}^{2}{ }_{\text {metal }} \mathrm{m}^{-2} \text { pellet }\right)\end{array}$ & $0.27 \pm 0.01$ & $0.12 \pm 0.01$ & $0.39 \pm 0.01$ & $0.25 \pm 0.01$ \\
\hline Unit cell parameter, $a(\mathrm{~nm})$ & - & - & 0.41752 & 0.83400 \\
\hline Active sites per unit cell, $k$ & - & - & 1 & 2 \\
\hline
\end{tabular}

software. Based on particle size and population, the exposed area of the particles may be calculated as (assuming the particles have hemispheric geometry). The results of this analysis are listed in Table 1.

\subsection{Catalytic Testing}

A continuous-flow, single-chamber reactor was used for the catalytic tests of the pellet samples. All experiments were conducted at atmospheric pressure. A schematic diagram of the reactor assembly is shown in Fig. 2a. Sample temperature was measured by using a K-type thermocouple, placed in proximity $(0.5 \mathrm{~cm}$ away) to the catalyst surface. The flow of the feeding gases was controlled by electronic mass flow controllers. The gases used were high purity $20 \% \mathrm{CO} / \mathrm{He}, 20 \% \mathrm{O}_{2} / \mathrm{He}$, and $\mathrm{CP}$ grade $\mathrm{He}(\mathrm{N} 5,99.999 \%$ minimum purity) provided by BOC Ltd. The total gas flow rate was kept constant at $1 \times 10^{-4}$ mol s${ }^{-1} \mathrm{~m}^{-2}\left(150 \mathrm{~cm}^{3} \mathrm{~min}^{-1}\right)$ measured at the outlet using a Varian digital flow meter (1000 series). The volumetric flow rates are given at normal temperature and pressure (NTP).

The $\mathrm{CO}_{2}$ mole fraction in the outlet steam was measured by an XTREAM-CO $\mathrm{CO}_{2}$ analyser (minimum detectable $\mathrm{CO}_{2}$ mole fraction was $1 \mathrm{ppm}$, which corresponds to a minimum measurable rate of $1 \times 10^{-10}$ mol s${ }^{-1}$ with a flow rate of $\left.1 \times 10^{-4} \mathrm{~mol} \mathrm{~s}^{-1}\right)$. The production rate of $\mathrm{CO}_{2}, r_{\mathrm{CO}_{2}}$, expressed in $\operatorname{mol}\left(\mathrm{CO}_{2}\right) \mathrm{s}^{-1}$, is calculated as shown in Eq. 1:

$r_{\mathrm{CO}_{2}}=y_{\mathrm{CO}_{2}} \cdot \dot{n}$

where $y_{\mathrm{CO}_{2}}$ is the measured $\mathrm{CO}_{2}$ mole fraction at the gas outlet, $\dot{n}$ is the molar flow. The production rate of $\mathrm{CO}_{2}$ was measured under "gradientless" conditions where the reactor was operated under differential conversion of CO $(30 \%$ conversion of $\mathrm{CO}$ or less).

The effect of temperature on the $r_{\mathrm{CO}_{2}}$ (henceforth referred to as a temperature dependence experiment), was studied by heating the catalysts under inlet gas mixture of $0.5 \% \mathrm{CO}$ and $0.25 \%, 1.33 \%$ or $3 \% \mathrm{O}_{2}$, from $80{ }^{\circ} \mathrm{C}$ up to $460{ }^{\circ} \mathrm{C}$, with $20{ }^{\circ} \mathrm{C}$ temperature steps and with a heating rate of $2{ }^{\circ} \mathrm{C}$ $\min ^{-1}$. At each temperature step, the temperature was held constant until steady-state was achieved, i.e., the $r_{\mathrm{CO}_{2}}$ did not vary by more than $\pm 5 \%$ over $60 \mathrm{~min}$. The effect of $\mathrm{CO}$ mole fraction on the $r_{\mathrm{CO}_{2}}$ (henceforth referred to as a $\mathrm{CO}$ mole fraction dependence experiment) was studied by holding the $\mathrm{O}_{2}$ inlet mole fraction constant at $0.25,1.33$ and $3 \%$, while the $\mathrm{CO}$ inlet mole fraction was varied between 0.5 and $18.9 \%$ at $292{ }^{\circ} \mathrm{C}$. The stability of the pellet samples was also investigated as a function of time. The $r_{\mathrm{CO}_{2}}$ was recorded over $170 \mathrm{~h}$ using an inlet feed gas mixture of $0.5 \% \mathrm{CO}$ and $0.25 \% \mathrm{O}_{2}$ at $450{ }^{\circ} \mathrm{C}$. It is worth noting that the same pellet
Fig. 2 Catalytic reactors. Schematics of a the continuous-flow single-chamber reactor and $\mathbf{b}$ of the fix packed-bed reactor. The reactor tube is made from quartz (inner diameter: $7 \mathrm{~mm}$ ) while equal amounts of quartz wool were placed in either side of the powder sample to immobilize the catalyst bed

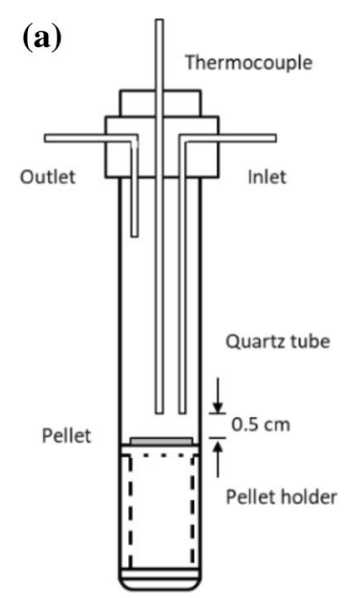

(b)

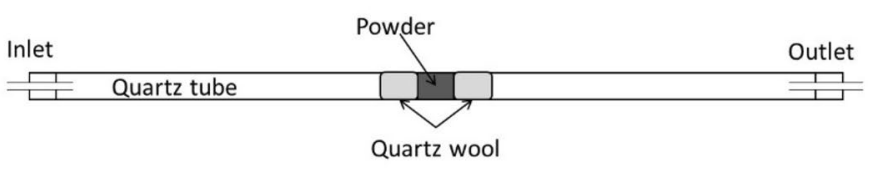


catalyst was used for the temperature dependence, $\mathrm{CO}$ mole fraction dependence and long-term stability studies.

The effect of sulphur poisoning on the $r_{\mathrm{CO}_{2}}$ was studied on powder samples $(10 \mathrm{mg})$. The study was performed in a fix packed-bed reactor (Fig. 2b), by introducing $50 \mathrm{ppm}$ $\mathrm{SO}_{2}$ a the inlet gas mixture of $0.6 \% \mathrm{CO}$ and $1 \% \mathrm{O}_{2}$, at time intervals of 15,30 and $60 \mathrm{~min}$, at $400{ }^{\circ} \mathrm{C}$ for $\mathrm{Ni} / \mathrm{p}$ and at $480{ }^{\circ} \mathrm{C}$ for $\mathrm{Fe}-\mathrm{Ni} / \mathrm{p}$. The higher temperature was chosen for the $\mathrm{Fe}-\mathrm{Ni} / \mathrm{p}$ catalyst in order to demonstrate the exceptional stability where deactivation due to particle agglomeration is reported in literature for base metal catalysts but still the sulphur poisoning effect is pronounced. For comparison, a commercial $66 \pm 5 \mathrm{wt} \% \mathrm{Ni} / \mathrm{Al}_{2} \mathrm{O}_{3}-\mathrm{SO}_{2}$ catalyst (Alfa Aesar) was tested under the same inlet gas mixture at $400{ }^{\circ} \mathrm{C}$. Volumetric dilution within the catalyst bed was made by mixing each catalyst powder with $\mathrm{Al}_{2} \mathrm{O}_{3}$ powder $(10 \mathrm{wt} \%$ of each catalyst is diluted with $\mathrm{Al}_{2} \mathrm{O}_{3}$ to get a total weight of $100 \mathrm{mg}$ ). It was found that this amount of catalyst sample mixed with $\mathrm{Al}_{2} \mathrm{O}_{3}$ resulted in a reasonable pressure drop within the bed. The total gas flow rate was kept constant at $3 \times 10^{-4} \mathrm{~mol} \mathrm{~s}^{-1}\left(450 \mathrm{~cm}^{3} \mathrm{~min}^{-1}\right.$, GHSV $\left.=26,000 \mathrm{~h}^{-1}\right)$. The $\mathrm{CO}_{2}$ mole fraction in the outlet steam was measured by an XTREAM- $\mathrm{CO}_{2}$ analyser (minimum detectable $\mathrm{CO}_{2}$ mole fraction was $1 \mathrm{ppm}$, which corresponds to a minimum measurable rate of $3 \times 10^{-10} \mathrm{~mol} \mathrm{~s}^{-1}$ with a flow rate of $3 \times 10^{-4} \mathrm{~mol} \mathrm{~s}^{-1}$ ). The production rate of $\mathrm{CO}_{2}$ was measured under "gradientless" conditions where the reactor was operated under differential conversion of $30 \% \mathrm{CO}$, hence the different operating temperatures for the three different powder samples.

Upstream to both reactors, a fixed-bed reactor with alumina powder heated at $90{ }^{\circ} \mathrm{C}$ was used to capture possible carbonyl species.

\section{Results and Discussion}

\subsection{Catalyst Microstructure}

Figure 3 shows the SEM micrographs of $\mathrm{Ni} / \mathrm{p}$ and $\mathrm{Fe}-\mathrm{Ni} / \mathrm{p}$ catalysts, in as-prepared state, as well as after temperature dependence catalytic experiments. The insets show the corresponding particle size histogram as measured by image analysis from the SEM micrographs, according to a method described in the Sect. 2 and in our previous work [2]. This method allowed us to calculate additional particle characteristics, such as particle size, population and exposed metal area per catalyst area, as summarised in Table 1. From Fig. 3 and Table 1 it is apparent that both $\mathrm{Ni} / \mathrm{p}$ and $\mathrm{Fe}-\mathrm{Ni} / \mathrm{p}$ catalysts display similar average particle size, with uniformly distributed particles, although the population of the $\mathrm{Fe}-\mathrm{Ni}$ particles is roughly half that of the Ni particles. The difference in particle population is, due, in part, to the $\mathrm{Fe}-\mathrm{Ni} / \mathrm{p}$ sample containing roughly half the amount of exsolvable ions as compared to $\mathrm{Ni} / \mathrm{p}$, and, in part due to the presence of $\mathrm{Sr}$ which is known
Fig. 3 Catalyst microstructure. SEM micrographs of the catalyst surface and corresponding particle size histograms for $\mathrm{Ni} / \mathrm{p}$, a as-prepared (metallic state) and $\mathbf{b}$ after temperature dependence study (oxidised state), and for $\mathrm{Fe}-\mathrm{Ni} / \mathrm{p}, \mathbf{c}$ asprepared (metallic state) and $\mathbf{d}$ after temperature dependence study (oxidised state) (a)

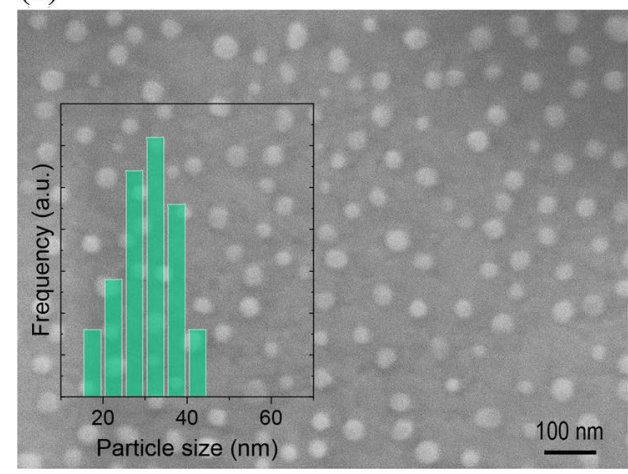

(b)

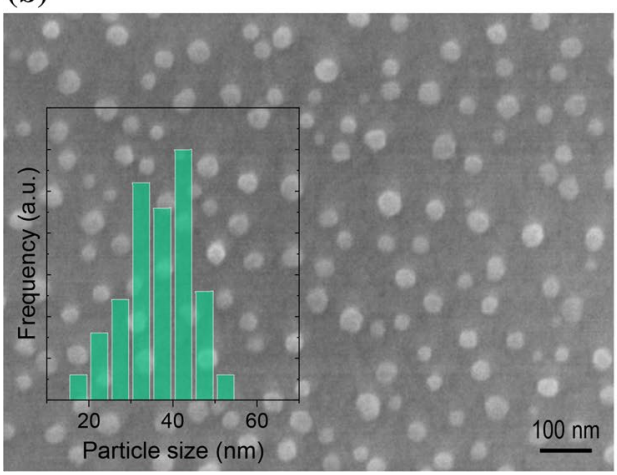

(c)

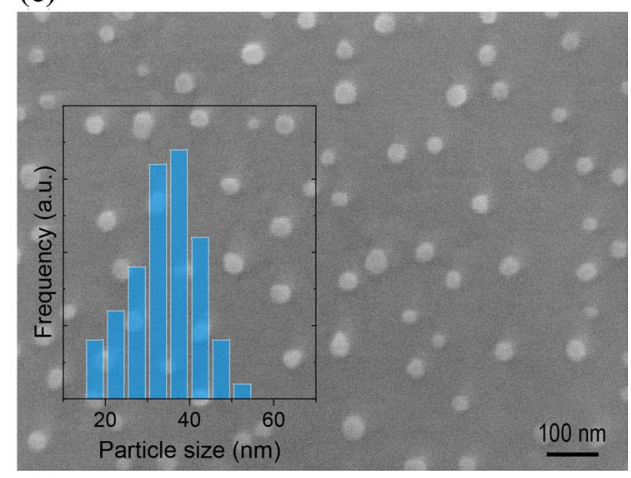

(d)

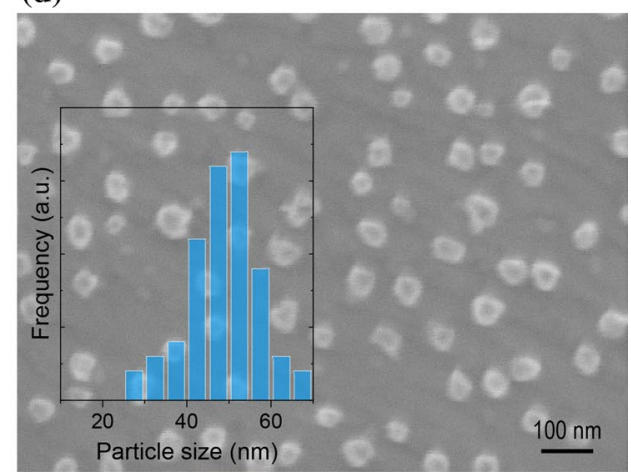


to limit exsolution (compare the initial stoichiometries, $\mathrm{La}_{0.8} \mathrm{Ce}_{0.1} \mathrm{Ni}_{0.4} \mathrm{Ti}_{0.6} \mathrm{O}_{3}$ vs. $\left.\mathrm{La}_{0.5} \mathrm{Sr}_{0.4} \mathrm{Fe}_{0.1} \mathrm{Ni}_{0.1} \mathrm{Ti}_{0.6} \mathrm{O}_{3}\right)[4,7]$.

\subsection{Catalytic Activity}

Figure 4a shows the $\mathrm{CO}_{2}$ production rate for the $\mathrm{CO}$ oxidation reaction, as a function of temperature, at three different inlet gas mixtures, for the $\mathrm{Ni} / \mathrm{p}$ and $\mathrm{Fe}-\mathrm{Ni} / \mathrm{p}$ catalysts. These rates were measure on cooling down, that is, after particles have undergone oxidation (see Fig. 3; Table 1 for particle microstructure and characteristics). The minimum temperature for a measurable $r_{\mathrm{CO}_{2}}$ was around $260{ }^{\circ} \mathrm{C}$ for both samples. Below $240{ }^{\circ} \mathrm{C}$, the $r_{\mathrm{CO}_{2}}$ was below the minimum measurable limit $\left(5 \times 10^{-6} \mathrm{mmol} \mathrm{s}^{-1}\right)$. For all the inlet gas mixtures, and for both catalysts, the activity increased upon increasing temperature. Under stoichiometric inlet feed conditions $\left(0.5 \% \mathrm{CO}, 0.25 \% \mathrm{O}_{2}\right)$ and below $380{ }^{\circ} \mathrm{C}$, the $\mathrm{CO}$ oxidation rates are similar for $\mathrm{Ni} / \mathrm{p}$ and $\mathrm{Fe}-\mathrm{Ni} / \mathrm{p}$ catalysts, while above $400{ }^{\circ} \mathrm{C}$, the $\mathrm{Fe}-\mathrm{Ni} / \mathrm{p}$ catalyst showed slightly higher $\mathrm{CO}_{2}$ production rates. Interestingly, under oxidising conditions $\left(0.5 \% \mathrm{CO}, 1.33 \% \mathrm{O}_{2}\right.$ or $\left.3 \% \mathrm{O}_{2}\right)$ the $\mathrm{Fe}-\mathrm{Ni} / \mathrm{p}$ catalyst exhibited up to twofold higher catalytic rates at temperatures above $400{ }^{\circ} \mathrm{C}$ as compared to the $\mathrm{Ni} / \mathrm{p}$ catalyst.

However, it should be noted that, as revealed by the microstructural analysis, the $\mathrm{Fe}-\mathrm{Ni} / \mathrm{p}$ sample exhibits roughly half the particle population as compared to $\mathrm{Ni} / \mathrm{p}$ (see Fig. 3; Table 1). In order to better compare the site activities of $\mathrm{Ni} / \mathrm{p}$ and $\mathrm{Fe}-\mathrm{Ni} / \mathrm{p}$ catalysts with each other and to the literature, we calculate their respective nTOFs for the $\mathrm{CO}$ oxidation reaction. For this, we assume that the active sites are associated with the metal oxide particles since, in the absence of exsolved nanoparticles, the samples displayed virtually no activity. In addition, lacking any further mechanistic evidence, we assume that each surface metal atom provides one active site. Furthermore, in order to calculate the nTOFs we combined the kinetic data in Fig. 4 with the particle analysis data obtained from SEM image analysis and summarised in Table 1. Thus, the number of reacted $\mathrm{CO}$ molecules per second, $N_{\mathrm{CO}}$, and the number of nominal active sites, $N_{\text {as }}$, are given by Eqs. (2) and (3), respectively:

$N_{\mathrm{CO}}=r_{\mathrm{CO}_{2}} \cdot N_{\mathrm{A}}$

$N_{\text {as }}=\frac{\left(A_{e} \cdot A\right)}{a^{2} \cdot k}$

where $r_{\mathrm{CO}_{2}}$ is the rate of $\mathrm{CO}_{2}$ production, $\mathrm{N}_{\mathrm{A}}$ is Avogadro's number, $\mathrm{A}$ is the catalyst area with exsolved nanoparticles in oxidised form (top of the pellet, see Fig. 1), $A_{e}$ is the exposed metal area per catalyst area (also in oxidised form), $a$ is the crystal lattice unit cell parameter of the particles and $k$ is the average number of metal sites per unit cell face (see Table 1). The crystalline facets of the particles were considered to be in a (100) termination, thus, for the $\mathrm{Ni}$, "NiO"-type rock-salt structure $k=1$ and for the $\mathrm{Fe}-\mathrm{Ni}$ spinel oxide, $\mathrm{AB}_{2} \mathrm{O}_{4}$-type structure $k=2$. The nTOF $\left(\right.$ in s $\left.^{-1}\right)$ can then be calculated by:

$\mathrm{nTOF}=\mathrm{N}_{\mathrm{A}} \cdot r_{\mathrm{CO}_{2}} \cdot a^{2} /\left(A_{e} \cdot A \cdot k\right)$

The corresponding nTOF values are plotted against temperature on the right $y$-axis in Fig. 4a for both catalysts. Consistent with a previous report [2], the nTOF values for both
Fig. 4 Catalytic activity. $\mathrm{CO}_{2}$ production rates for $\mathrm{CO}$ oxidation, for $\mathrm{Ni} / \mathrm{p}$ and $\mathrm{Fe}-\mathrm{Ni} / \mathrm{p}$ as a function of a temperature and $\mathbf{b} \mathrm{CO}$ mole fraction $y_{\mathrm{CO}}$, at $292{ }^{\circ} \mathrm{C}$. Inlet feed gas mixtures were $0.5 \% \mathrm{CO}$, with $0.25 \%$, $1.33 \%$ and $3.0 \% \mathrm{O}_{2}$ and total gas flow rate of $150 \mathrm{~mL} \mathrm{~min}^{-1}$. The right $y$-axis shows corresponding nTOF values calculated based on the characteristics of the particles on oxide form (Table 1) (a)

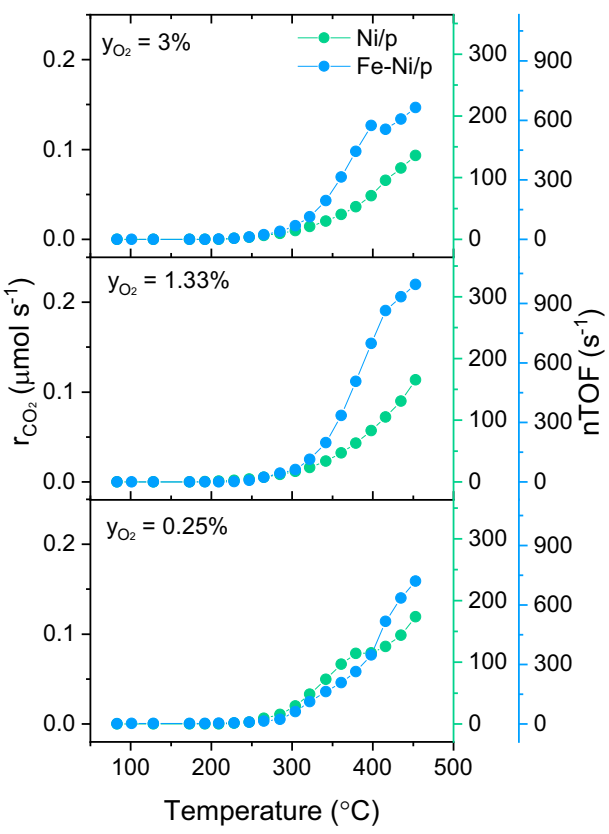

(b)

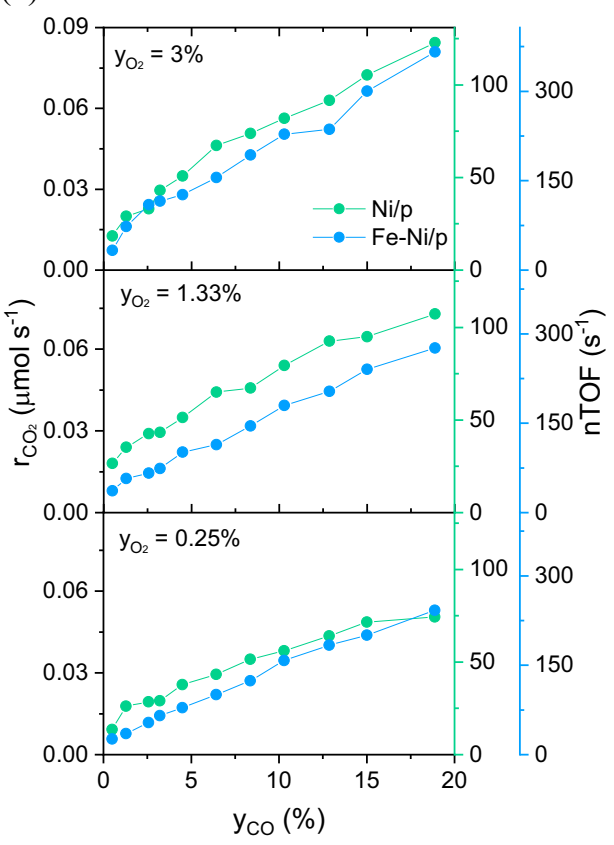


exsolved catalysts are of the order of several hundred of $\mathrm{s}^{-1}$. Interestingly though, under the same conditions, the nTOF values for $\mathrm{Fe}-\mathrm{Ni} / \mathrm{p}$ are roughly three times higher as compare to $\mathrm{Ni} / \mathrm{p}$. This difference largely originates in the fact that the particle population of the $\mathrm{Fe}-\mathrm{Ni} / \mathrm{p}$ sample is roughly half that of the Ni/p sample (see Table 1). These results indicate that the activity of Ni-based exsolved nanoparticles for the $\mathrm{CO}$ oxidation reaction can be further enhanced by alloying with other earth-abundant metals such as $\mathrm{Fe}$. The $\mathrm{Fe}-\mathrm{Ni} / \mathrm{p}$ catalysts exhibited nTOF values of up to $1000 \mathrm{~s}^{-1}$ at $460{ }^{\circ} \mathrm{C}$ $\left(0.5 \% \mathrm{CO}, 1.33 \% \mathrm{O}_{2}\right)$. This is a few orders of magnitude higher than values reported in literature for base metal and metal oxide nanoparticles [3].

The microstructure of the samples after the temperature dependence experiment is shown in Fig. 3. The nanoparticles expanded and displayed more faceted shapes as a result of undergoing oxidation. For $\mathrm{Ni} / \mathrm{p}$, the average particle size increased from $\sim 31$ to $\sim 35 \mathrm{~nm}$. The size increase $(35 \mathrm{~nm} / 31 \mathrm{~nm}=1.13)$ is similar to what is expected from the lattice expansion of $\mathrm{Ni}^{0}$ to $\mathrm{NiO}$ following oxidation (4.175 $\AA / 3.523 \AA=1.18$ ). For $\mathrm{Fe}-\mathrm{Ni} / \mathrm{p}$, the average particle size increased by a larger factor, from $\sim 35$ to $\sim 50 \mathrm{~nm}$ $(50 \mathrm{~nm} / 35 \mathrm{~nm}=1.43)$. This increase is consistent with a lattice expansion from $\mathrm{Fe}$-rich, $\mathrm{Fe}-\mathrm{Ni}$ alloys in a body centred cubic structure (e.g. $\sim 2.88 \AA$ ) to mixed oxides of $\mathrm{Fe}-\mathrm{Ni}$ (> $8.34 \AA$ ), which would give a ratio of 1.45 [19]. It is also worth noting that the nanoparticle populations in $\mathrm{Ni} / \mathrm{p}$ and $\mathrm{Fe}-\mathrm{Ni} / \mathrm{p}$ remain essentially unchanged following the temperature-dependence catalytic tests, indicating that the particles did not agglomerate as reported for other systems prepared by conventional routes [20].

Figure $4 \mathrm{~b}$ shows the $\mathrm{CO}_{2}$ production rate (left y-axis) and the corresponding nTOF values (right y-axis) as a function of CO mole fraction $\left(y_{\mathrm{CO}}\right)$, for both catalysts, at $292{ }^{\circ} \mathrm{C}$, under three different inlet gas mixtures. Upon increasing the $\mathrm{CO}$ mole fraction, both catalysts displayed monotonically increasing catalytic rates. For $\mathrm{Ni} / \mathrm{p}$, the corresponding nTOF values varied between 75 and $125 \mathrm{~s}^{-1}$ when the mole fraction of $\mathrm{O}_{2}\left(y_{\mathrm{O}_{2}}\right)$ varies from 0.25 to $3 \%$ (at $y_{\mathrm{CO}}=18.8 \%$ ). Under the same conditions the oxidized $\mathrm{Fe}-\mathrm{Ni} / \mathrm{p}$ catalyst displayed similar reaction rates but higher nTOF values (230-370 s ${ }^{-1}$ ) as compared to the Ni catalyst. It is worth mentioning that no change in particle characteristics and no carbon formation were detected by SEM (not shown here) after this experiment for either $\mathrm{Ni} / \mathrm{p}$ and $\mathrm{Fe}-\mathrm{Ni} / \mathrm{p}$. This is in contrast to base metal/metal oxide nanoparticles prepared by conventional methods which generally agglomerate and/or coke under such experimental conditions [4, 21,22].

\subsection{Catalyst Durability}

To investigate the stability of the $\mathrm{Fe}-\mathrm{Ni}$ system as compared to its $\mathrm{Ni}$ variant we measured the catalytic activity of both

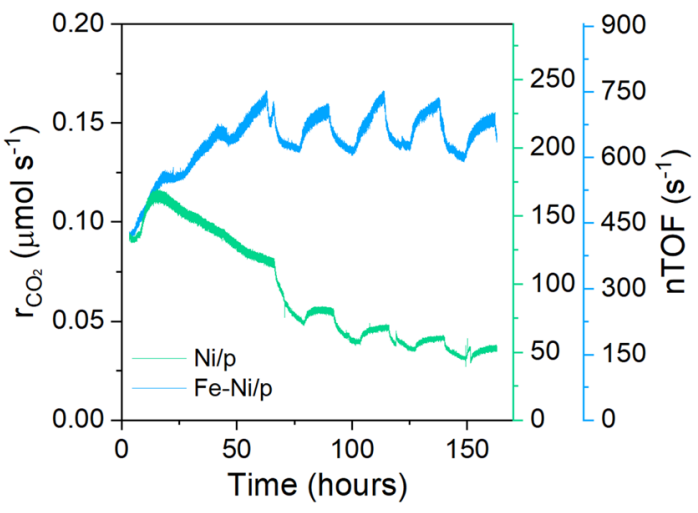

Fig. 5 Long term catalytic activity. $\mathrm{CO}_{2}$ production rates as a function of time at $450{ }^{\circ} \mathrm{C}$ over $\mathrm{Ni} / \mathrm{p}$ and $\mathrm{Fe}-\mathrm{Ni} / \mathrm{p}$ catalysts, for $\mathrm{CO}$ oxidation, with inlet gas mixture of $0.6 \% \mathrm{CO}$ and $1 \% \mathrm{O}_{2}$ and total gas flow rate of $450 \mathrm{~mL} \mathrm{~min}^{-1}$. The right y-axis shows corresponding nTOF values calculated based on the characteristics of the particles on oxide form (Table 1). The oscillations may be due to temperature and pressure fluctuations in the lab over $24 \mathrm{~h}$ periods affecting the volumes of the gasses

systems over $170 \mathrm{~h}$ of continuous testing, at $450{ }^{\circ} \mathrm{C}$ (Fig. 5). It should be noted that in this test we used the same pellet catalysts used for the temperature dependence test as well as the $\mathrm{CO}$ mole fraction dependence test. It can be seen that the catalytic activity of the Ni catalyst degraded over the first $120 \mathrm{~h}$ of testing. After this initial loss of activity, the $\mathrm{Ni}$ catalyst appeared to stabilise, however an almost twofold drop in the catalytic activity was observed over this period. On the contrary, the catalytic activity of the $\mathrm{Fe}-\mathrm{Ni} / \mathrm{p}$ sample improved over the first $50 \mathrm{~h}$ of testing and was maintained over the remaining testing time. It is worth noting that under these testing conditions typical based metal nanostructured catalysts deactivate via agglomeration in a matter of a few hours [23, 24]. However, the $\mathrm{Fe}-\mathrm{Ni} / \mathrm{p}$ exsolved system used in this study outperforms previous base metal systems for oxidation reactions in terms of activity and long-term stability. Our $\mathrm{Fe}-\mathrm{Ni} / \mathrm{p}$ catalyst is able to operate at high temperature for close to $200 \mathrm{~h}$, conditions which are usually not reported in similar studies in literature even though are of practical importance in base metal catalysis [23, 25, 26]. Furthermore, the catalytic activity, in terms of TOFs, even after $170 \mathrm{~h}$ of continuous testing is of the order of $600 \mathrm{~s}^{-1}$, which is significantly higher than those generally measured for mixed oxide base metal systems [26, 27].

\subsection{Sulphur Tolerance}

To investigate the effect of sulphur poisoning, we compared the $\mathrm{Ni} / \mathrm{p}$ and $\mathrm{Fe}-\mathrm{Ni} / \mathrm{p}$ catalysts against a state-of-the-art $\mathrm{Ni} /$ $\mathrm{Al}_{2} \mathrm{O}_{3} / \mathrm{SiO}_{2}$ catalyst (henceforth referred as "commercial $\mathrm{Ni}$ catalyst") on a weight-by-weight basis $(10 \mathrm{mg})$. Nickelbased catalysts are known to be very sensitive to sulphur 
(a)

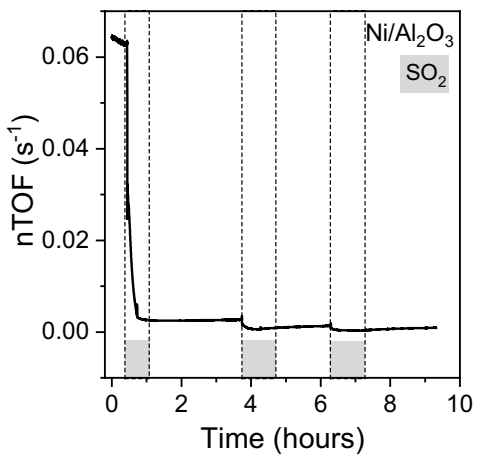

(b)

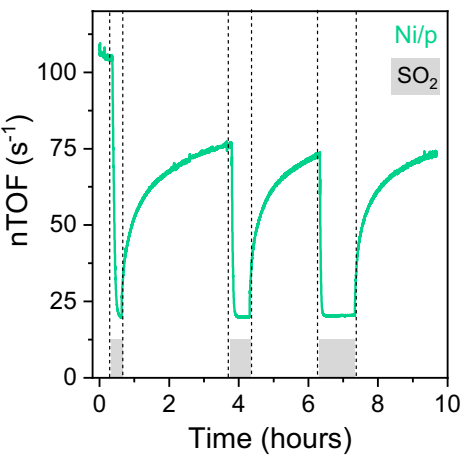

(c)

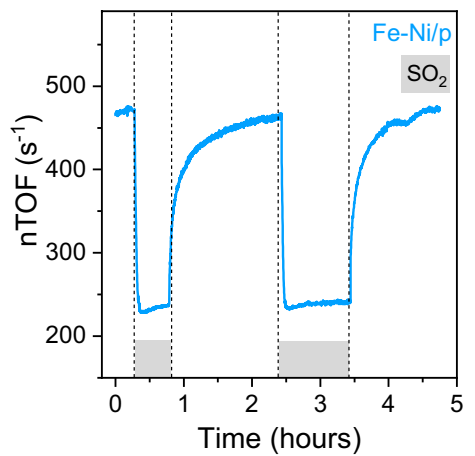

Fig. $6 \mathrm{SO}_{2}$ poisoning. nTOF values for $\mathrm{CO}_{2}$ production during introduction of $50 \mathrm{ppm} \mathrm{SO}_{2}$ in an inlet gas mixture of $0.6 \% \mathrm{CO}$ and $1 \% \mathrm{O}_{2}$ at time intervals of 15,30 and 60 min (grey-marked regions) over a

compounds and even a few ppm of sulphur species can cause irreversible poisoning. Although the poisoning mechanism is not well understood, some reports assign the irreversible poisoning effect of sulphur compounds to Ni-based catalysts to the formation of inactive $\mathrm{Ni}_{3} \mathrm{~S}_{2}$ surface species, formation of bulk Ni-S species (at concentrations above $100 \mathrm{ppm}$ ) and the S-induced reconstruction of the Ni surface [28, 29]. To study the effect of sulphur poisoning, $50 \mathrm{ppm} \mathrm{SO}_{2}$ were added sequentially for 15,30 and $60 \mathrm{~min}$ in an inlet gas mixture of $0.6 \% \mathrm{CO}$ and $1 \% \mathrm{O}_{2}$ and we recorded the nTOFs before, during and after the $\mathrm{SO}_{2}$ exposure (Fig. 6). We expect that $\mathrm{SO}_{2}$ at this concentration and temperatures below $500{ }^{\circ} \mathrm{C}$ will poison effectively the $\mathrm{CO}$ oxidation rates [30,31]. Prior to poisoning the recorded rates correspond to around $30 \% \mathrm{CO}$ conversion or less for all tested systems. Upon introducing the $\mathrm{SO}_{2}$ in the reaction mixture for $15 \mathrm{~min}$, the commercial $\mathrm{Ni}$ catalyst showed an instant decrease in nTOF values from $7 \times 10^{-2}$ to $3 \times 10^{-3} \mathrm{~s}^{-1}$ ( 95\% decrease) (Fig. 6a). After removing the $\mathrm{SO}_{2}$ from the feed, the nTOF values did not recover but remained stable at $3 \times 10^{-3} \mathrm{~s}^{-1}$. Under the same conditions, the nTOF values appear to decrease for the $\mathrm{Ni} / \mathrm{p}$ catalyst from 110 to $18 \mathrm{~s}^{-1}$ ( 83\% decrease). However, the nTOF values recovered partly, to about $68 \%\left(75 \mathrm{~s}^{-1}\right)$ of the initial values, when $\mathrm{SO}_{2}$ was removed from the feed (Fig. 6b). Interestingly, under the same conditions, for the $\mathrm{Fe}-\mathrm{Ni} / \mathrm{p}$ catalyst, even though the nTOFs decreased by $50 \%$ during the $15 \mathrm{~min}$ of $\mathrm{SO}_{2}$ exposure, after removing the $\mathrm{SO}_{2}$ from the feed, approximately $98 \%$ of the initial activity is eventually restored (Fig. 6c). This finding holds great practical importance because it unlocks new areas of application for these systems.
$\mathrm{Ni} / \mathrm{Al}_{2} \mathrm{O}_{3}-\mathrm{SiO}_{2}$ at $400{ }^{\circ} \mathrm{C}$, b Ni/p at $400{ }^{\circ} \mathrm{C}$ and $\mathbf{c} \mathrm{Fe}-\mathrm{Ni} / \mathrm{p}$ at $480{ }^{\circ} \mathrm{C}$.

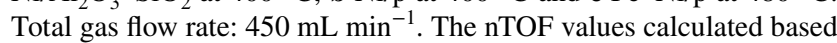
on the characteristics of the particles on oxide form (Table 1)

\section{Conclusions}

In summary, we demonstrated that the catalytic activity of exsolved Ni nanoparticles can be greatly enhanced when $\mathrm{Fe}$ is used as an alloy metal. We believe that this superior catalytic activity and long-term stability of the $\mathrm{Fe}-\mathrm{Ni}$ system is achieved by preserving the initial spatial arrangement and avoiding surface reconstruction in combination with the confined nature of the exsolved nanoparticles. Our findings also demonstrate that alloying and confinement of nanoparticles enhances site activities even under sulphur poisoning environments in base metal systems for $\mathrm{CO}$ oxidation reaction at temperature.

Acknowledgements The research leading to these results has received funding from the European Research Council under the European Union's Seventh Framework Programme (FP/2007-2013)/ERC Grant Agreement Number 320725 and from the EPSRC via the research grants EP/P024807/1, EP/P009050/1, EP/P007767/1, EP/J016454/1 and $\mathrm{EP} / \mathrm{L} 017008 / 1$. Data supporting this publication is openly available under an 'Open Data Commons Open Database License'. Additional metadata are available at: https://doi.org/10.17634/161340-1.

Open Access This article is distributed under the terms of the Creative Commons Attribution 4.0 International License (http://creativeco mmons.org/licenses/by/4.0/), which permits unrestricted use, distribution, and reproduction in any medium, provided you give appropriate credit to the original author(s) and the source, provide a link to the Creative Commons license, and indicate if changes were made.

\section{References}

1. Kaspar J, Fornasiero P, Hickey N (2003) Automotive catalytic converters: current status and some perspectives. Catal Today 77(4):419-449

2. Neagu D, Papaioannou EI, Ramli WKW, Miller DN, Murdoch BJ, Menard H, Umar A, Barlow AJ, Cumpson PJ, Irvine JTS, Metcalfe IS (2017) Demonstration of chemistry at a point through 
restructuring and catalytic activation at anchored nanoparticles. Nat Commun 8:1855

3. An K, Alayoglu S, Musselwhite N, Plamthottam S, Melaet G, Lindeman AE, Somorjai GA (2013) Enhanced CO oxidation rates at the interface of mesoporous oxides and Pt nanoparticles. J Am Chem Soc 135(44):16689-16696

4. Neagu D, Oh TS, Miller DN, Menard H, Bukhari SM, Gamble SR, Gorte RJ, Vohs JM, Irvine JTS (2015) Nano-socketed nickel particles with enhanced coking resistance grown in situ by redox exsolution. Nat Commun 6:8120

5. Oh TS, Rahani EK, Neagu D, Irvine JTS, Shenoy VB, Gorte RJ, Vohs JM (2015) Evidence and model for strain-driven release of metal nanocatalysts from perovskites during exsolution. J Phys Chem Lett 6(24):5106-5110

6. Hui JN, Neagu D, Miller DN, Yue XL, Ni CS, Irvine JTS (2018) Metal-oxide interactions for infiltrated Ni nanoparticles on A-site deficient LaxSr1-3x/2TiO . Solid State Ionics 315:126-130

7. Neagu D, Tsekouras G, Miller DN, Menard H, Irvine JTS (2013) In situ growth of nanoparticles through control of non-stoichiometry. Nat Chem 5(11):916-923

8. Thormahlen P, Skoglundh M, Fridell E, Andersson B (1999) Low-temperature $\mathrm{CO}$ oxidation over platinum and cobalt oxide catalysts. J Catal 188:300-310

9. Zubenko D, Singh S, Rosen BA (2017) Exsolution of Re-alloy catalysts with enhanced stability for methane dry reforming. Appl Catal B 209:711-719

10. Liu SB, Liu QX, Luo JL (2016) CO2-to-CO conversion on layered perovskite with in situ exsolved Co-Fe alloy nanoparticles: an active and stable cathode for solid oxide electrolysis cells. J Mater Chem A 4(44):17521-17528

11. Bligaard T, Norskov JK (2007) Ligand effects in heterogeneous catalysis and electrochemistry. Electrochim Acta 52(18):5512-5516

12. Kitla A, Safonova OV, Fottinger K (2013) Infrared studies on bimetallic copper/nickel catalysts supported on zirconia and ceria/ zirconia. Catal Letters 143(6):517-530

13. Gonzalez-delaCruz VM, Pereniguez R, Ternero F, Holgado JP, Caballero A (2012) In situ XAS study of synergic effects on $\mathrm{Ni}-\mathrm{Co} / \mathrm{ZrO}_{2}$ methane reforming catalysts. J Phys Chem C 116:2919-2926

14. Gu JZYW, Tao FF (2012) Shape control of bimetallic nanocatalysts through well-designed colloidal chemistry approaches. Chem Soc Rev 41(24):8050-8065

15. Tao FF (2012) Synthesis, catalysis, surface chemistry and structure of bimetallic nanocatalysts. Chem Soc Rev 41(24):7977-7979

16. Xie X, Li Y, Liu ZQ, Haruta M, Shen W (2009) Low-temperature oxidation of $\mathrm{CO}$ catalysed by $\mathrm{Co}(3) \mathrm{O}(4)$ nanorods. Nature 458(7239):746-749
17. Biabani-Ravandi A, Rezaei M (2012) Low temperature CO oxidation over Fe-Co mixed oxide nanocatalysts. Chem Eng J 184:141-146

18. Jian-Liang Cao G-JL, Wang Y, Sun G, Wang X-D, Hari B, Zhang Z-Y (2014) Mesoporous Co-Fe-O nanocatalysts: preparation, characterization and catalytic carbon monoxide oxidation. J Environ Chem Eng 2:477-489

19. Bieniek B, Pohl D, Schultz L, Rellinghaus B (2011) The effect of oxidation on the surface-near lattice relaxation in FeNi nanoparticles. J Nanopart Res 13(11):5935-5946

20. Dai S, Zhang SY, Katz MB, Graham GW, Pan XQ (2017) In situ observation of $\mathrm{Rh}-\mathrm{CaTiO}_{3}$ catalysts during reduction and oxidation treatments by transmission electron microscopy. ACS Catal 7(3):1579-1582

21. Wallace WT, Min BK, Goodman DW (2005) The nucleation, growth, and stability of oxide-supported metal clusters. Top Catal 34(1-4):17-30

22. Jiang SP (2012) Nanoscale and nano-structured electrodes of solid oxide fuel cells by infiltration: advances and challenges. Int J Hydrogen Energy 37(1):449-470

23. Royer S, Duprez D (2011) Catalytic oxidation of carbon monoxide over transition metal oxides. Chemcatchem 3(1):24-65

24. Jansson J, Palmqvist AEC, Fridell E, Skoglundh M, Osterlund L, Thormahlen P, Langer V (2002) On the catalytic activity of $\mathrm{Co}_{3} \mathrm{O}_{4}$ in low-temperature CO oxidation. J Catal 211(2):387-397

25. Jiang YA, Liu BD, Yang LN, Yang B, Liu XY, Liu LS, Weimer C, Jiang $X$ (2015) Size-controllable Ni5TiO7 nanowires as promising catalysts for CO oxidation. Sci Rep-UK 5:14330

26. Nikolla E, Schwank J, Linic S (2007) Promotion of the long-term stability of reforming Ni catalysts by surface alloying. J Catal 250(1):85-93

27. Nikolla E, Holewinski A, Schwank J, Linic S (2006) Controlling carbon surface chemistry by alloying: carbon tolerant reforming catalyst. J Am Chem Soc 128(35):11354-11355

28. Chen IW, Shiue DW (1988) Resistivity to sulfur poisoning of nickel alumina catalysts. Ind Eng Chem Res 27(8):1391-1396

29. Kuhn JN, Lakshminarayanan N, Ozkan US (2008) Effect of hydrogen sulfide on the catalytic activity of Ni-YSZ cermets. J Mol Catal A 282(1-2):9-21

30. Vielstich W, Gaste HA, Harumi Y (2009) Handbook of fuel cells: fundamentals technology and applications, vol 5. In Vielstich W, Lamm A, Gaste HA (eds) Advances in electrocatalysis, materials, diagnostics and durability. Wiley, Oxford

31. Hepola J, Simell P (1997) Sulphur poisoning of nickel-based hot gas cleaning catalysts in synthetic gasification gas-I. Effect of different process parameters. Appl Catal B 14(3-4):287-303 